\title{
Multiple Tooth-Rowed Parareptile From the Early Permian of Oklahoma
}

\author{
Dylan C. T. Rowe ${ }^{1}$, Diane M. Scott ${ }^{1}$, Joseph J. Bevitt ${ }^{2}$ and Robert R. Reisz ${ }^{1,3 *}$ \\ ${ }^{1}$ Department of Biology, University of Toronto Mississauga, Mississauga, ON, Canada, ${ }^{2}$ Australian Centre for Neutron Scanning, \\ Australian Nuclear Science and Technology Organisation, Sydney, NSW, Australia, ${ }^{3}$ International Centre of Future Science, \\ Dinosaur Evolution Research Center, Jilin University, Changchun, China
}

OPEN ACCESS

Edited by:

Nathalie Bardet,

UMR7207 Centre de recherche sur la paléobiodiversité et les paléoenvironnements (CR2P), France

Reviewed by: Juan Carlos Cisneros, Federal University of Piauí, Brazil Aaron R. H. LeBlanc, King's College London, United Kingdom

*Correspondence: Robert R. Reisz robert.reisz@utoronto.ca

Specialty section: This article was submitted to Paleontology,

a section of the journal Frontiers in Earth Science

Received: 14 May 2021 Accepted: 10 August 2021 Published: 25 August 2021

Citation:

Rowe DCT, Scott DM, Bevitt JJ and Reisz RR (2021) Multiple Tooth-Rowed

Parareptile From the Early Permian of Oklahoma.

Front. Earth Sci. 9:709497. doi: 10.3389/feart.2021.709497
The Dolese Limestone Quarry near Richards Spur, Oklahoma includes an elaborate system of caves which have been infilled with early Permian fossil rich sediments. In operation for more than a century, the quarry yielded vast numbers of disarticulated skeletal elements of the most diverse assemblage of fully terrestrial tetrapods from the Paleozoic. Excavations carried out in this century are distinct in producing large numbers of articulated and semiarticulated skeletons, including numerous new taxa. Dolese is therefore unique among early Permian localities in being home to a diverse assemblage of small parareptiles, including two species of Delorhynchus. Here we describe a new species of acleistorhinid, characterized by the presence of multiple tooth rows on the dentary, that can be identified with confidence as a third new species of Delorhynchus. The multiple tooth rowed condition is deemed not to be a pathological condition, and appears to have formed in the same manner as in the captorhinid eureptile Captorhinus aguti through uneven growth of the tooth-bearing element.

Keywords: acleistorhinid parareptile, dental battery, early permian, Oklahoma, new taxon

\section{INTRODUCTION}

The Richards Spur locality in Oklahoma, also known as the Dolese Brothers limestone quarry, is a highly fossiliferous site containing an unparalleled variety of early Permian tetrapods (Modesto, 1999; MacDougall and Reisz, 2012; MacDougall et al., 2016). Investigation of the site's geology and taphonomy has revealed an extensive karst system within Ordovician strata, filled with clay and mudstone deposited 289 to 286 million year ago (Sullivan et al., 2000; Woodhead et al., 2010; MacDougall et al., 2017). The entirety of fossil material collected from Richards Spur originates from these fissures, with varying degrees of articulation and wear present (MacDougall et al., 2017). Over forty distinct tetrapod taxa of small to medium body size have been identified from within the locality, with a large number of endemic taxa distinct from other lower Permian assemblages (Sullivan et al., 2000; MacDougall et al., 2017). Of the numerous tetrapod taxa found in Richards Spur, eight are assigned to Parareptilia (Vaughn, 1958; Fox, 1962; Reisz et al., 2002; Tsuji et al., 2010; MacDougall and Reisz, 2012; MacDougall and Reisz, 2014; Reisz et al., 2014; MacDougall et al., 2016).

Parareptilia comprises one of the major amniote clades of the Permian, possessing a wide variety of distinct morphologies and distributed globally (Debraga and Reisz, 1996; MacDougall et al., 2019). This clade of amniotes originated as small-bodied carnivores, but experienced significant increases in diversity throughout the Permian (Reisz et al., 2015; MacDougall et al., 2019). Relative completeness of some parareptilian remains has enabled identification of diverse morphologies including small 
carnivores, aquatic filter-feeders, and megaherbivores (Lee, 1999; Reisz et al., 2002; Modesto, 2006; Cisneros, 2008; Tsuji et al., 2012; MacDougall and Reisz, 2014; LeBlanc and Reisz, 2015; Verrière et al., 2016). Parareptiles were also diverse in body size, with skulls between 2 and $45 \mathrm{~cm}$ in length (Lee, 1999; Berman et al., 2000). In the Early Permian, parareptiles were relatively small with skulls at or under $5 \mathrm{~cm}$ in length (Modesto et al., 2009). The frequency of parareptilian remains in Richards Spur is unusual given their sparse occurrence in most other deposits of similar age (Cope, 1878; Tsuji et al., 2010). Many parareptiles found within Richards Spur belonged to the small-bodied Acleistorhinidae (Vaughn, 1958; Fox, 1962; Daly, 1969; Modesto, 1999; Tsuji et al., 2012; Reisz et al., 2014; MacDougall et al., 2016). While the majority of acleistorhinid species have been found within Oklahoma, remains have also been found in Nova Scotia, Ohio and even in Brazil (Mann et al., 2019; Cisneros et al., 2020b). Acleistorhinids can be traced back as far as the late Carboniferous, and were most likely insectivorous in general based upon tooth morphology and even associated remains of insect cuticle (Modesto et al., 2009; Mann et al., 2019). The occurrence of numerous acleistorhinid species in a relatively small geographical area has led to the hypothesis that it was a hotspot for parareptile diversification (MacDougall et al., 2016).

One acleistorhinid identified from Richards Spur is Delorhynchus, which was first described as a "pelycosaur" based on an isolated maxilla (Fox, 1962). Reclassification of the "protorothyridid" Colobomycter pholeter as an acleistorhinid also tentatively identified $D$. priscus as a sister taxon to C. pholeter and Acleistorhinus pteroticus (Modesto, 1999). Evidence of an insect-based diet was supported by small, sharp marginal dentition and, more remarkably, the discovery of arthropod cuticle in the oral region of cranial material that has since been assigned to Delorhynchus (Modesto et al., 2009; Reisz et al., 2014). The discovery of a partial skeleton and skull resulted in the subsequent description of a new species of Delorhynchus, D. cifelli, and placement of Delorhynchus within the Acleistorhinidae (Reisz et al., 2014). Further studies have resulted in a potential ontogenetic sequence of jugal morphology and implications for closure of the temporal fenestra, as well as evidence of multiple denticulate coronoids previously unseen in reptiles (Haridy et al., 2016, Haridy et al., 2018). The "microsaur" Bolterpeton carrolli from Richards Spur, described on the basis of a mandibular fragment, was also reassigned to D. cifelli (Anderson and Reisz, 2003; Haridy et al., 2018). In this paper, we report the discovery of mandibular and cranial material that in most aspects closely resembles previously described specimens of $D$. cifelli. However, in contrast to other referred specimens of Delorhynchus, a double row of dentary teeth is present. The addition of this novel taxon further contributes to the considerable parareptile diversity present at Richards Spur, as well as a novel occurrence of multiple tooth rows within the Parareptilia.

\section{SYSTEMATIC PALEONTOLOGY}

PARAREPTILIA Olson, 1947. PROCOLOPHONOMORPHA Romer, 1964.
ANKYRAMORPHA deBraga and Reisz, 1996.

DELORHYNCHUS Fox, 1962.

DELORHYNCHUS MULTIDENTATUS, sp. nov. (Figure 1).

Holotype-ROMVP 87042-fragmentary skull.

Diagnosis-Acleistorhinid parareptile characterized by the presence of distinct, separate rows of teeth on the dentary, and an enlarged labial foramen on the dentary. Similar to Delorhynchus cifelli in the presence of distinct tuberculous ornamentation of the skull roof elements. Differs from $D$. cifelli in the more bulbous shape of the dentary teeth, with little or no evidence of recurvature.

Locality and Horizon-Dolese Brothers Quarry near Richards Spur, Oklahoma, United States Lower Permian/ Cisuralian (289 Ma).

Etymology-Specific epithet refers to the diagnostic feature of this taxon.

\section{METHODS}

Non-destructive, thermal-neutron microtomographic measurement of specimen (ROMVP 87042) was performed using the DINGO thermal neutron radiography/tomography/ imaging station, located at the $20 \mathrm{MW}$ Open- Pool Australian Lightwater (OPAL) reactor housed at the Australian Nuclear Science and Technology Organisation (ANSTO), Lucas Heights, New South Wales, Australia.

For this study, DINGO was equipped with an Iris 15 sCMOS camera (16-bit, 5,056 × 2,960 pixels) coupled with a Makro Planar $100 \mathrm{~mm}$ Carl Zeiss lens and a $20 \mu \mathrm{m}$ thick terbium-doped Gadox scintillator screen (Gd2O2S:Tb, RC Tritec AG) to yield a pixel size of $13.7 \times 13.7 \mu \mathrm{m}$ and field of view was of $40.6 \times 69.3 \mathrm{~mm}^{2}$. DINGO was operated in high-flux mode, with a collimation ratio $(\mathrm{L} / \mathrm{D})$ of 500 was used, where $\mathrm{L}$ is the neutron aperture-to-sample length and $\mathrm{D}$ is the neutron aperture diameter, supplying a flux at sample of $4.75 \times 107 \mathrm{ncm}-2 \mathrm{~s}-1$ (Garbe et al., 2015). The tomographic scan consisted of a total of 1,440 equally-spaced angle shadow-radiographs obtained every $0.125^{\circ}$ as the sample was rotated $180^{\circ}$ about its vertical axis, which was positioned $15 \mathrm{~mm}$ from the detector face. Both dark (closed shutter) and beam profile (open shutter) images were obtained for calibration before initiating shadow-radiograph acquisition. To reduce anomalous noise, a total of three individual radiographs with an exposure length of $12.5 \mathrm{~s}$ were acquired at each angle (Mays et al., 2017). Total scan time was $16.5 \mathrm{~h}$.

Neutron activation of the specimen was measured by surface contact using an appropriate hand-held dosimeter, 35 min upon completion of the scan, at 4 days, and 2 weeks post-scan. The recordings were 13,1 and $0 \mu \mathrm{Sv} / \mathrm{h}$, respectively. The specimen was issued a radiation clearance certificate and cleared for return to the authors shortly thereafter, with no detectable counts per second above background recorded by the health physics surveyor.

The individual radiographs were summed in post-acquisition processing using the Grouped ZProjector function, and anomalous white-spots removed using a threshold filter in 

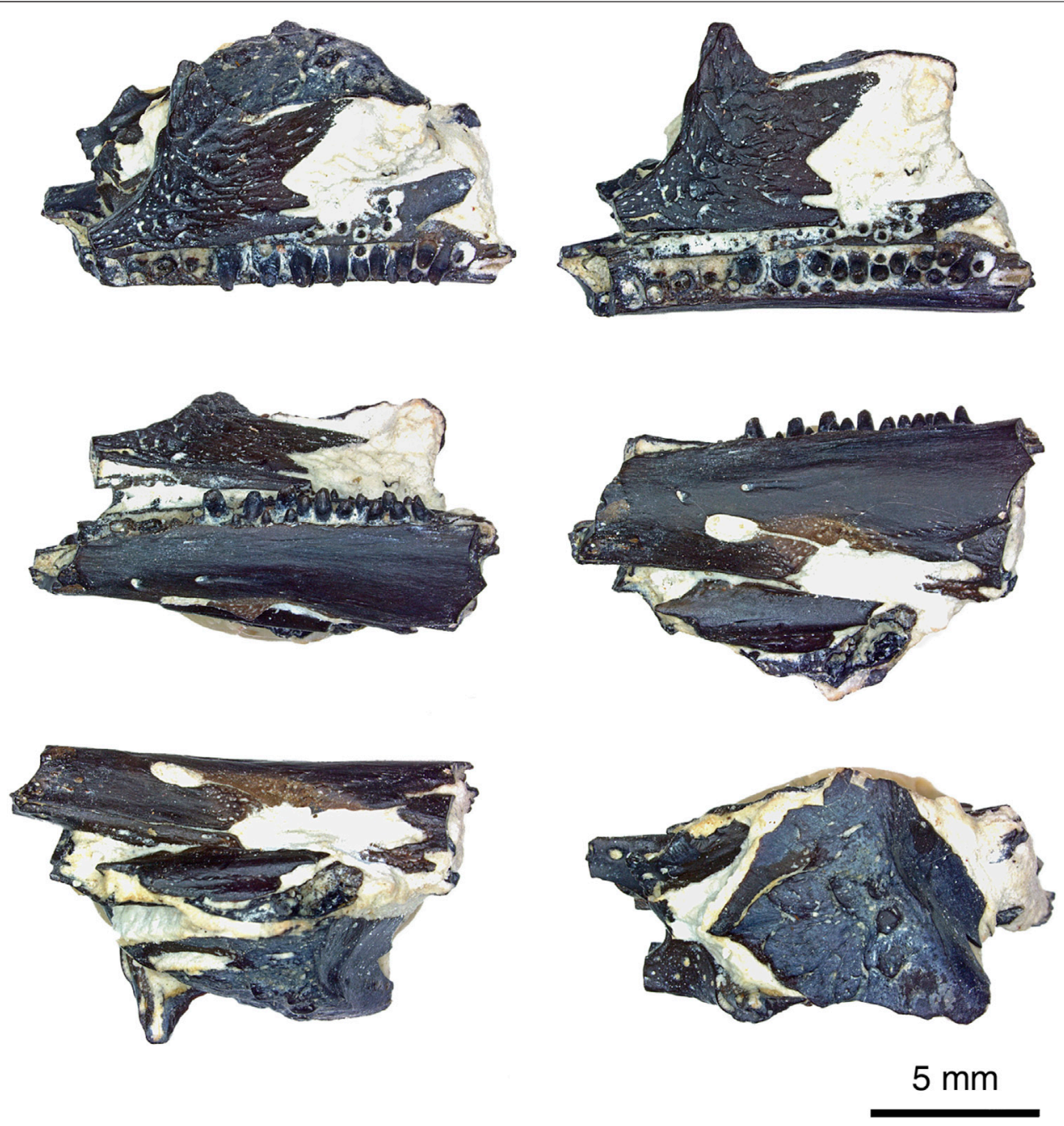

FIGURE 1 | Delorhynchus multidentatus, sp. nov., ROMVP 87042 in rotation from dorsal to ventral views of specimen, photographed by Diane Scott. Scale bar $=5 \mathrm{~mm}$.

ImageJ v.1.51 h. Normalisation and tomographic reconstruction of the 16-bit raw data were performed using Octopus Reconstruction v.8.8 (Inside Matters NV), yielding virtual slices perpendicular to the rotation axis. Prior to segmentation, the specimen scan was processed in ImageJ. Thorough segmentation of the specimen was performed on Avizo Lite registered to R. R. Reisz, and the model was compared to other specimens of $D$. cifelli specimens OMNH 73362 and OMNH 73363 for identification purposes. Photographs of the specimen were taken using a Leica microscope and associated software. Figures were assembled using Adobe Photoshop Elements 8.0.

\section{DESCRIPTION}

This holotype specimen is composed of a partial left mandibular fragment, two dentigerous palatal elements, two cranial elements and other small cranial fragments (see Figures 1-4 for visualization). The mandibular fragment belongs to the left side of the cranium and possesses a readily identifiable dentary, coronoid and splenial. Fragmentation of the posterolingual section results in numerous mandibular fragments which cannot be confidently identified. Surrounding the mandible fragment are a mostly complete jugal and squamosal, both from the left side of the skull. Ventral to the jugal and squamosal are small fragments of cranial material belonging to the ectopterygoid and pterygoid, as well as a fragment of the posterior splenial. The close association of these elements and the known breakages suggest that this specimen represents the remnants of a single skull. It is likely that the specimen was discovered as a fragment, and was a complete or near-complete skull damaged during the excavation process normally carried out by the limestone quarrying operations.

The dentary fragment in this specimen comprises the majority of the articulated mandibular fragment and possesses a dental 


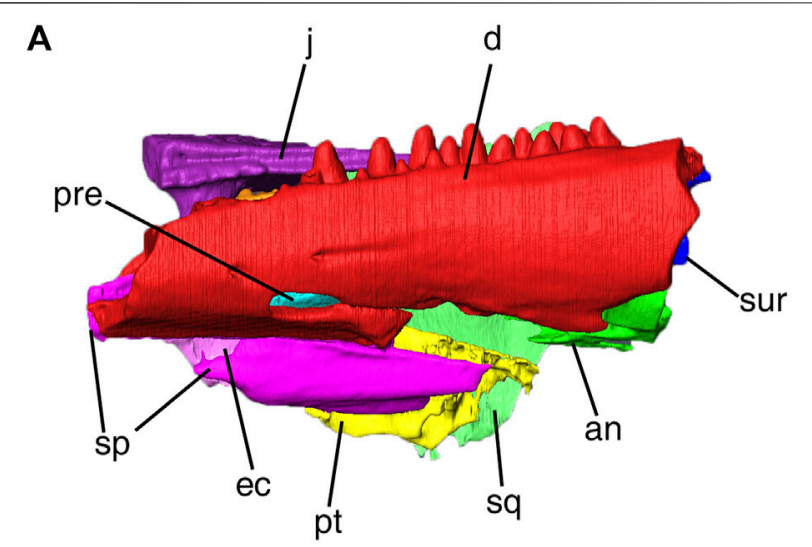

B

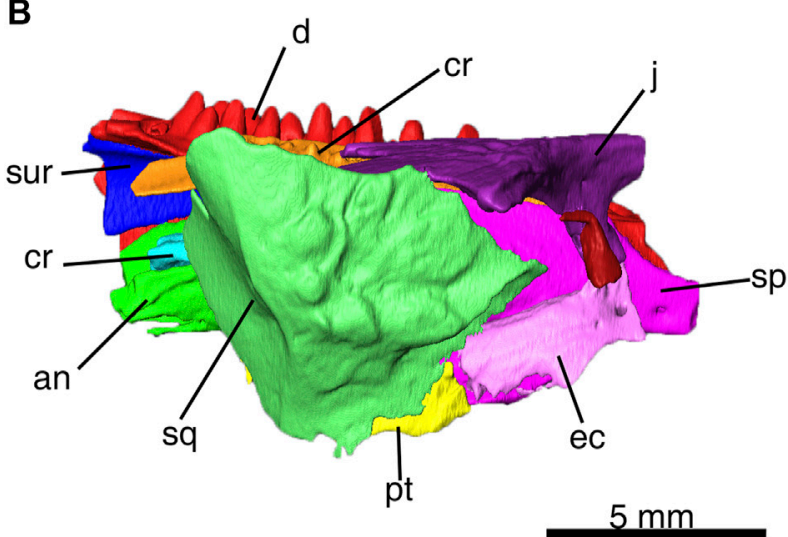

FIGURE 2 | Delorhynchus multidentatus, sp. nov., ROMVP 87042 as three-dimensional model from CT image sequence. (A) lateral, and (B) medial views of ROMVP 87042. Scale bar $=5 \mathrm{~mm}$. Abbreviations: an, angular; $\mathrm{cr}$, coronoid; d, dentary, ec, ectopterygoid; j, jugal; pre, prearticular; pt, pterygoid; sp, splenial; sq, squamosal; sur, surangular.

pattern not seen in previous Delorhynchus material. While other specimens of $D$. cifelli possess a single row of dentary teeth, this specimen instead possesses two rows, hereafter referred to as lingual and labial. A total of twenty-five sockets are present within the preserved fragment, with thirteen sockets assigned to the lingual row and twelve in the labial row. The anterior region of the dentary possesses two shallow labial foramina as well as a much wider and deeper foramen which entirely passes through the dentary and is comparable to a small mandibular fenestra. All foramina (shown in Figures 1, 2) possess shallow channels that extend posteriorly, which have propagated into a fracture towards adjacent breakage for the large foramen. Other specimens of Delorhynchus possess similar small and shallow foramina within the anterior dentary, but none are similar in size to the large foramen of this specimen (Reisz et al., 2014; Haridy et al., 2016, Haridy et al., 2018). In lateral view, the anterior half of the dentary is underlain by the splenial, but is not underlain posterolaterally due to fragmentation of the splenial.

The two rows of teeth present in the dentary are closely spaced, to the point that teeth from both rows intersect with one another. Dentary teeth present in this specimen are robust and possess little or no recurvation, although they are also damaged due to post-depositional processes. The first three lingual and first four labial sockets either lack teeth or contain broken teeth, as well as lingual sockets 6 and 10 and labial socket 13. The central region of the dentary fragment, specifically lingual teeth five to eight and labial teeth five to seven possesses both the largest and smallest teeth ,respectively. Towards the posterior, the lingual teeth decrease in size and the labial teeth correspondingly increase in size. Lingual tooth nine is unique in that it is significantly wider than other lingual teeth in the same region, to the point that it occupies two sockets. The enhanced size of this tooth may have been caused by early loss of a labial tooth, and the subsequent growth of the adjacent lingual tooth to fill the gap. Towards the back of the fragment, labial teeth 8-12 and lingual teeth 10-13 are immediately adjacent to one another and are equal in size. Upon detailed examination of the dentition, some of the posterior lingual teeth have eaten away at the adjacent labial teeth (see Figure 4), which indicates that the lingual teeth are comparatively younger. In addition, the observed size disparity between the dentary rows towards the central regions, with more worn-down labial teeth and larger lingual teeth towards the front, suggests that both rows of teeth are sequentially older towards the front. The combination of sequential replacement and erosion of labial teeth indicates that each row undergoes replacement at different times from the anterior to the posterior, which follows the general amniote pattern (Whitlock and Richman, 2013).

Comparisons between dentary teeth of Delorhynchus multidentatus and D. cifelli reveal notable differences in tooth morphology, as displayed in Figure 5. Teeth from D. cifelli are approximately twice as wide and two to three times as long as corresponding teeth from D. multidentatus. In addition, the teeth from $D$. multidentatus are proportionately larger than the teeth in D. cifelli as shown in Figure $\mathbf{5 A}$, most likely as a result of the additional tooth row. While most of the teeth of $D$. multidentatus are damaged due to post-depositional processes, two dentary teeth are intact and comparisons of fine details can be made with D. cifelli. The teeth from this new taxon possess a bulbous morphology, and possess more widely spaced and reduced fluting than teeth from previous mandibular specimens of Delorhynchus. Cutting edges are present in D. multidentatus, but unlike $D$. cifelli the teeth are not pointed as visualized in Figure 5B. The dentary of $D$. multidentatus additionally possesses a wider alveolar shelf than in D. cifelli, as shown in Figure 6.

Of the two coronoid ossifications observed in Delorhynchus specimens, only the anterior coronoid ossification is preserved within the holotype of $D$. multidentatus. This bone is mostly complete, with a small break in the anterior region. Similar to specimens of $D$. cifelli, the coronoid possesses extensive dentition. The posterior end of the anterior coronoid ossification terminates in a winglike projection which extends posteroventrally and lacks dentition. In specimens of $D$. cifelli, this extension is ventral to the anterior projection of the second coronoid ossification, and it can therefore be assumed that a more complete specimen of $D$. multidentatus would be similar in morphology.

In other Delorhynchus cifelli material, the splenial underlies the dentary anteriorly and the surangular posteriorly, comprising the ventral and lingual mandibular surfaces (Reisz et al., 2014; Haridy et al., 2018). This element is superficial in nature, has a 


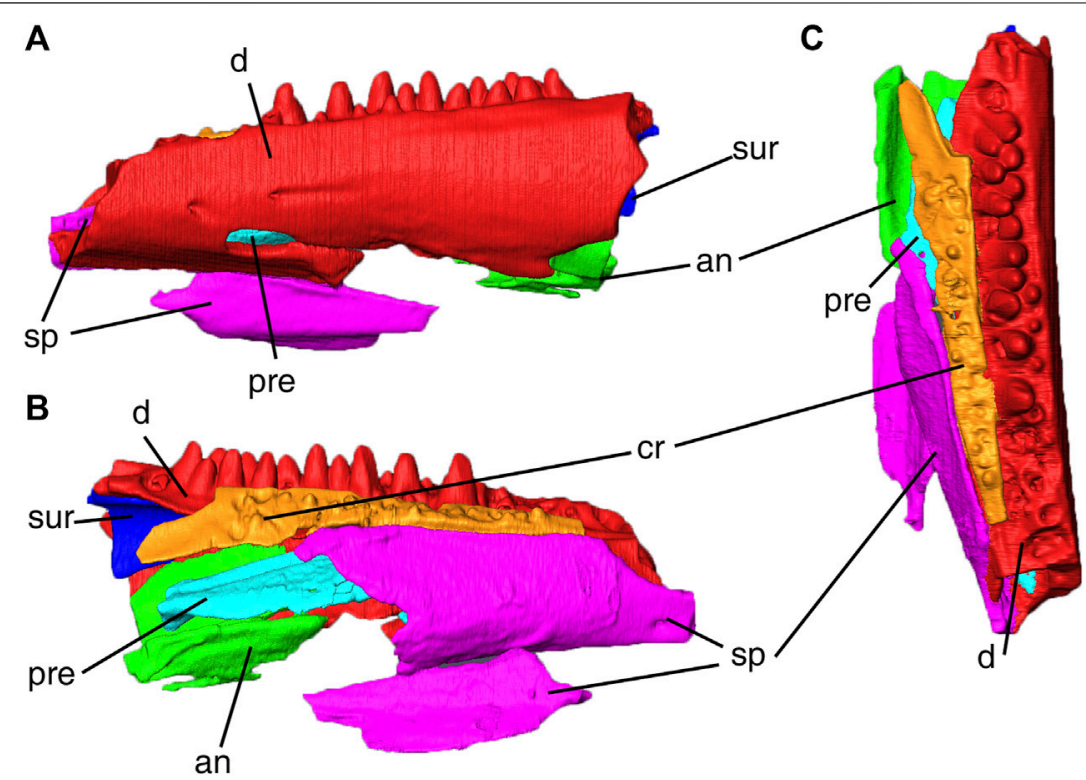

D

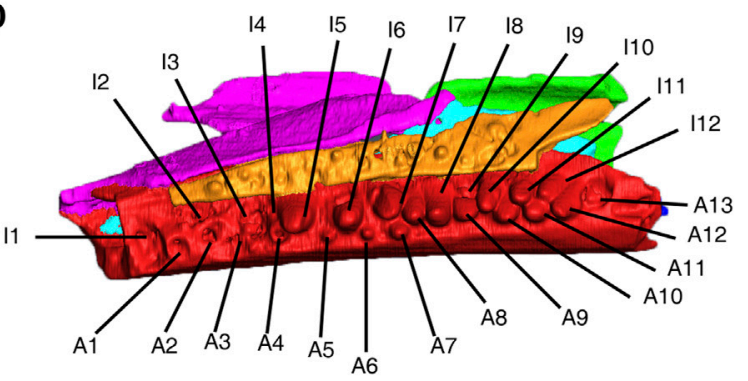

$5 \mathrm{~mm}$

FIGURE 3 | Delorhynchus multidentatus, sp. nov., ROMVP 87042. (A) labial, (B) lingual and (C) occlusal views of partial mandible. (D) occlusal view of partial mandible with numbering of tooth positions Scale bar = $5 \mathrm{~mm}$. Abbreviations: A1-A13, labial tooth positions 1-12, an, angular; cr, coronoid; d, dentary; I1-I12, lingual tooth positions 1-12; pre, prearticular; sp, splenial; sur, surangular.

smooth texture and possesses two anterior projections that join onto the dentary (Haridy et al., 2018). In this specimen, the splenial is only in articulation with the anterior half of the mandible. Towards the posterior, the splenial has been broken off and is found in association with the anteroventral region of the specimen. The anterior fragment sutures onto the dentary both dorsally and ventrally, as well as the coronoid dorsally. The disarticulated posterior splenial fragment would possess similar contacts with the dentary.

Angular elements in specimens of Delorhynchus cifelli are dorsally curved, and extend from the inside of the anterior mandible out to form part of the posterolabial surface of the mandible (Reisz et al., 2014; Haridy et al., 2018). In full articulation, the angular contacts the dentary and splenial anteriorly, the surangular dorsally and the articular posteriorly (Haridy et al., 2018). For this specimen, the angular has been disarticulated, and is present within the posteroventral region of the mandibular fragment. Identification of the angular is based on curvature, although much of the element has been fragmented and is missing.

The surangular has been described as a complex element that contributes to multiple characteristics of the lower jaw of
Delorhynchus cifelli (Haridy et al., 2018). These features include a posterior sheet which overlies the articular labially, part of the labial component of the coronoid process, and the internal wall of the adductor fossa (Reisz et al., 2014; Haridy et al., 2018). In addition, a thin anterior process underlies the dentary, which terminates at the anterior process of the posterior coronoid (Haridy et al., 2018). A small portion of the surangular element has been identified in the posterodorsal region in the holotype of D. multidentatus, and based upon the narrow sheetlike appearance it likely belongs to the anterior surangular process.

In Delorhynchus cifelli, the prearticular is wedged between the splenial and the posterior coronoid process, and borders the splenial, angular and intermandibularis foramen caudalis ventrally (Haridy et al., 2018). This lingual element is thin and elongated, and also possesses a well-defined ridge that forms a slanted shelf in the posterior prearticular (Haridy et al., 2018). As is the case with the angular, the prearticular has been disarticulated and fragmented, and is framed within the articulated dentary and splenial. Identification of the prearticular was based on its thinness and sharp ridge.

In this specimen, the left jugal has suffered slight anterior breakage, but is otherwise mostly complete as shown in Figure 7. 

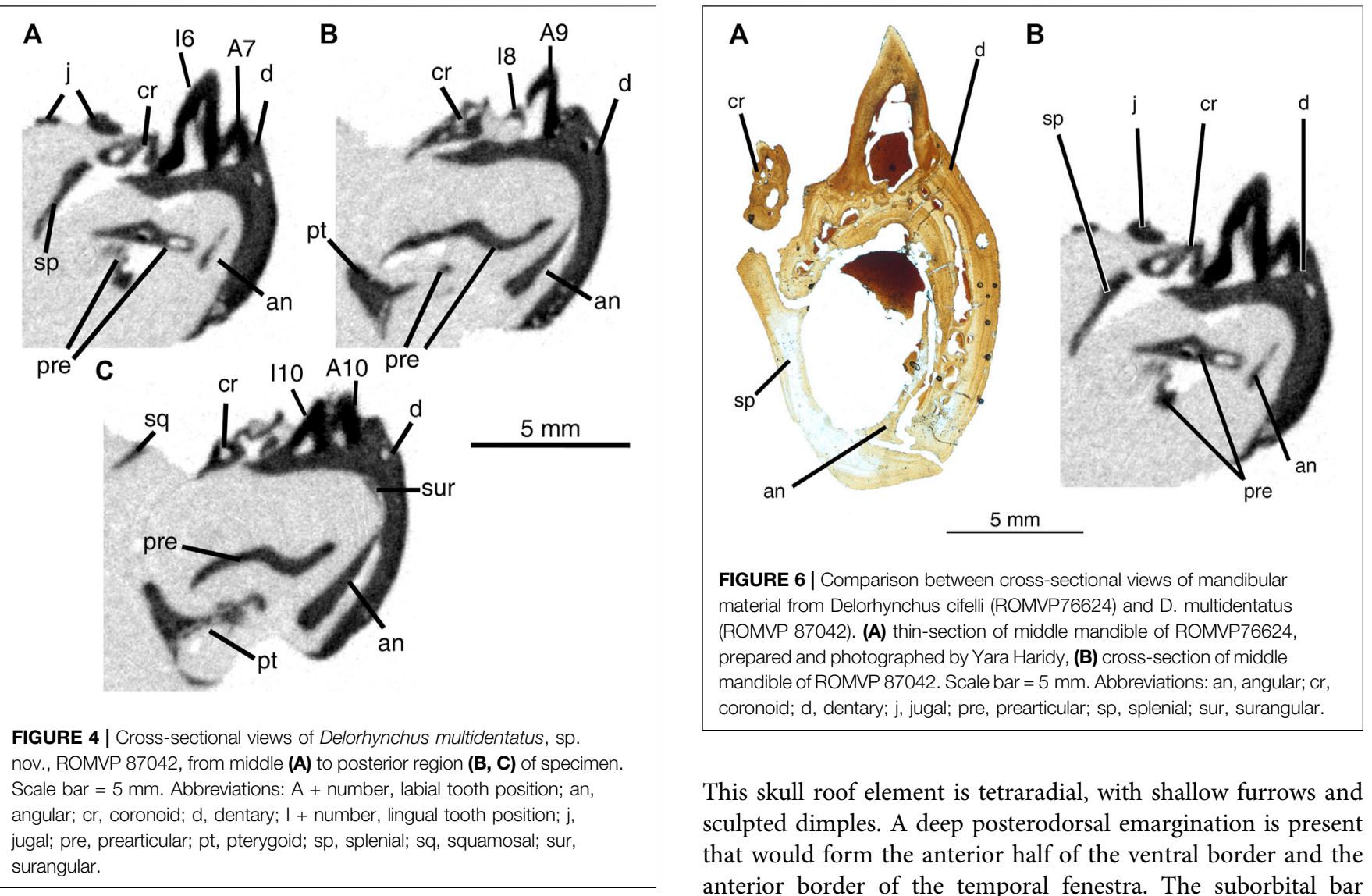

This skull roof element is tetraradial, with shallow furrows and sculpted dimples. A deep posterodorsal emargination is present that would form the anterior half of the ventral border and the anterior border of the temporal fenestra. The suborbital bar

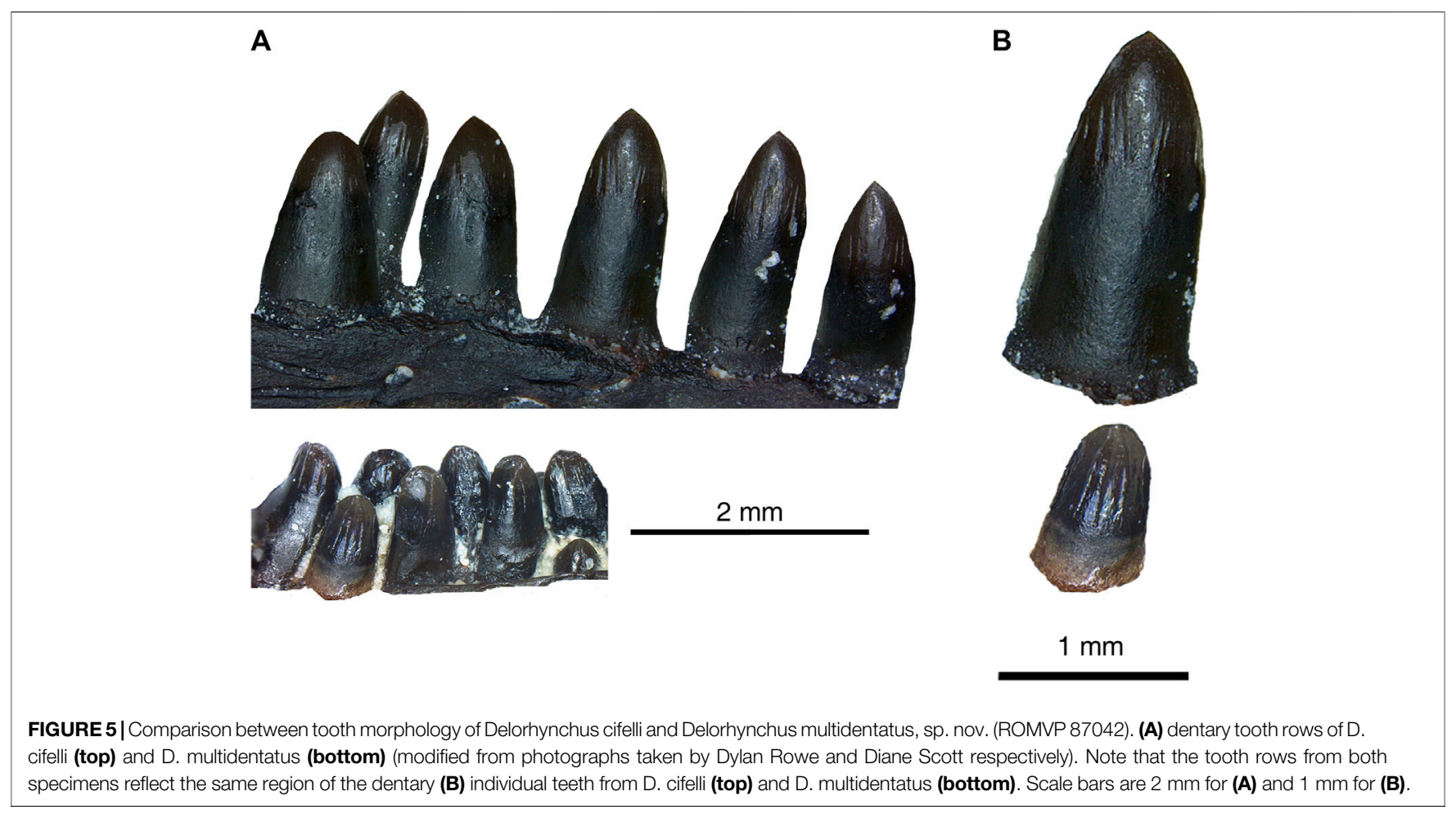



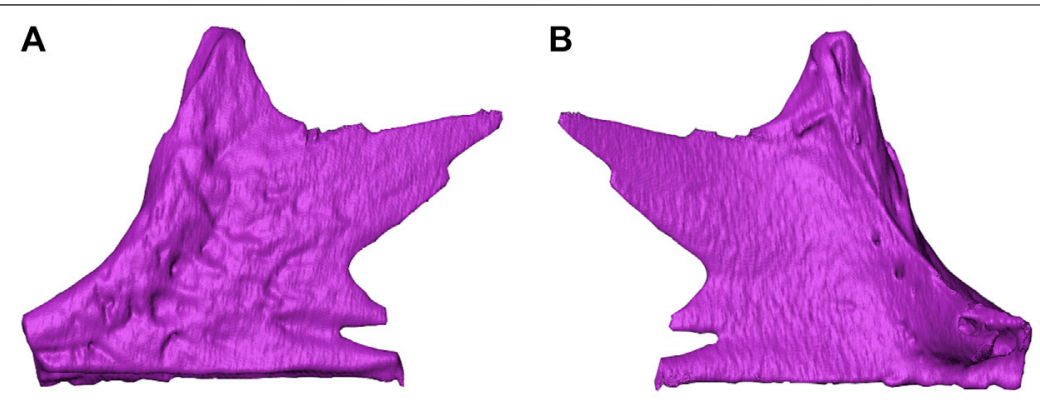

C
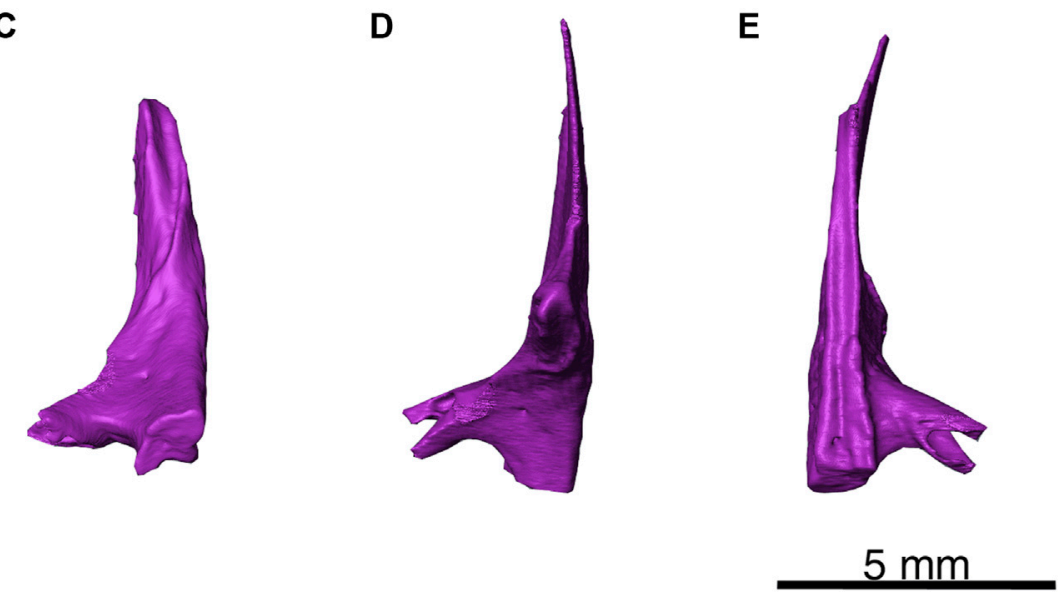

FIGURE 7 | Delorhynchus multidentatus, sp. nov., ROMVP 87042. (A) lateral, (B) medial, (C) anterior, (D) dorsal and (E) ventral views of left jugal. Scale bar $=5 \mathrm{~mm}$.

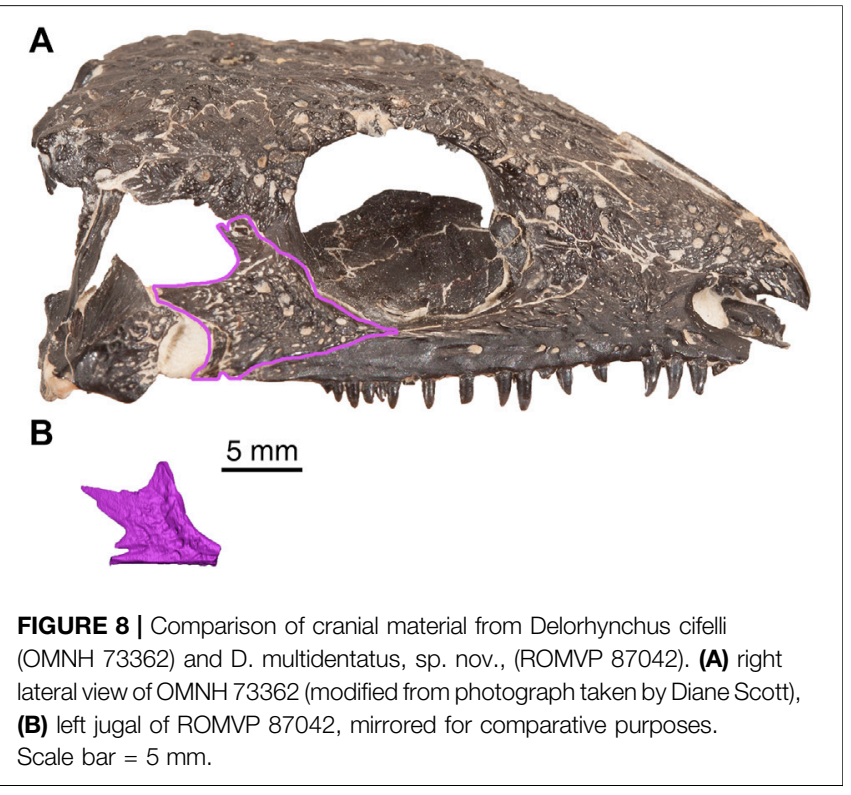

terminates in a break, immediately anterior to an incomplete wedge-shaped alary process that extends medially. Comparison with a previously presented ontogenetic sequence of Delorhynchus cifelli, as well as a skull as shown in Figure 8 indicate that the jugal morphology of $D$. multidentatus most closely resembled the most mature specimens of D. cifelli (Haridy et al., 2016). However, the jugal of $D$. multidentatus was significantly smaller, which reflects an adult specimen of comparatively smaller size. It is largely in position relative to the mandibular fragment, but is rotated such that it forms the most dorsal region of the specimen.

The left squamosal (see Figure 9 for visualization) is a tall element and possesses a rosette-shaped pattern of large tuberosities on the lateral surface that would cover other elements of the skull roof. In addition, the posterior surface is smooth and concave, as in previously described specimens of Delorhynchus cifelli. This specimen also possesses a shelf on the dorsal region, which would suture onto the supratemporal. Towards the posteroventral region, a small groove is present which would suture onto the quadratojugal.

Within the palate of Delorhynchus cifelli, the ectopterygoid makes a minor contribution to palatal dentition, nestled among the palatine, pterygoid, maxilla, and jugal (Reisz et al., 2014). Only a small number of denticles are present on the ventral surface, which is dominated by a large, but very shallow concavity (Reisz et al., 2014). While this element is predominantly thin, it also has thickened lateral and posterior margins (Reisz et al., 2014). The tentatively identified ectopterygoid in this specimen is only partial, and its medial surface has been broken. The ventral surface of the ectopterygoid can be clearly identified based on a small cluster of palatal teeth that are partially disarticulated, as 

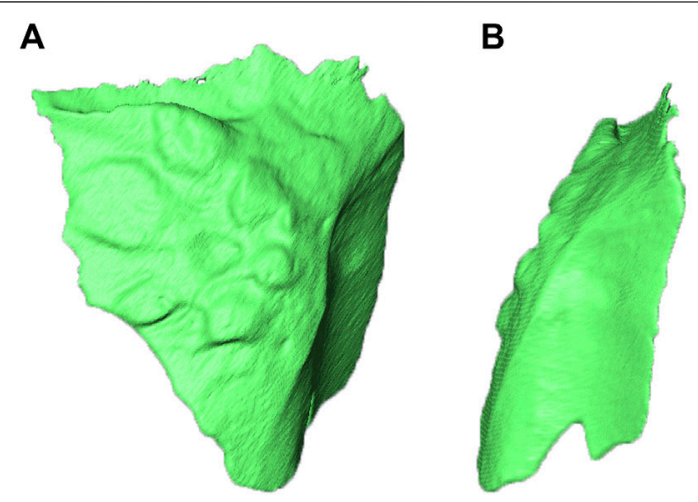

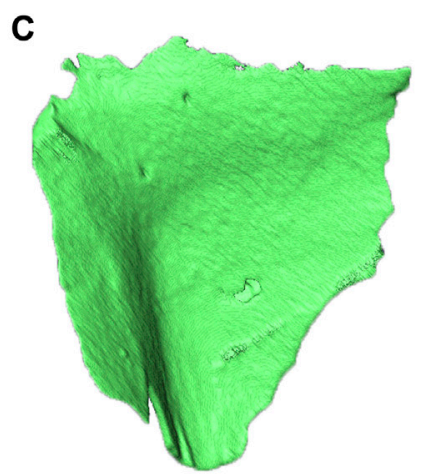

$5 \mathrm{~mm}$

FIGURE 9 | Delorhynchus multidentatus, sp. nov., ROMVP 87042. (A) lateral, (B) posterior and (C) medial views of left squamosal. Scale bar $=5 \mathrm{~mm}$.

well as two small denticles that are fully articulated. A thickened process present on the ectopterygoid would form a lateral contact with the medial process of the jugal.

In contrast to the ectopterygoid, the pterygoid makes a much larger contribution to the palatal dentition of Delorhynchus cifelli (Reisz et al., 2014). This element is highly complex, and can be subdivided into an anterior process, an angular transverse process and a posterior quadrate ramus (Reisz et al., 2014). In the holotype of $\mathrm{D}$. multidentatus, the tentatively identified left pterygoid is only present as a section of the transverse process, based on the sharply concave groove which is also present in $D$. cifelli. Only one denticle is present towards the posterior region, and the anterior region of the preserved element is highly fragmented.

\section{DISCUSSION}

This specimen can be readily identified as a distinct new taxon. This conclusion is based on the unique combination of a wide alveolar shelf on the dentary, multiple rows of dentary teeth, small size and ornamentation of the dentary. With the description of Delorhynchus multidentatus, there are now three members of the Delorhynchus genus, all located entirely within the Richards Spur cave system (Fox, 1962; Reisz et al., 2014). With the associated remains of insect cuticle with $D$. cifelli and comparable dentition in each species, all members of Delorhynchus were therefore small-bodied and insectivorous (Modesto et al., 2009). With the discovery of $D$. multidentatus, there are now nine distinct species of parareptiles within five genera from the Richards Spur locality (Vaughn, 1958; Fox, 1962; Reisz et al., 2002, 2014; Tsuji et al., 2010; MacDougall and Reisz, 2012; MacDougall et al., 2016). It must be noted that comparison with D. priscus is not possible, given that a single maxilla was assigned as the holotype of $D$. priscus and no maxilla has been preserved with the holotype of D. multidentatus (Fox, 1962). The known skull and mandibular elements are similar to those known in $D$. cifelli, but only a single row of dentary teeth are present in that species (Modesto et al., 2009; Reisz et al., 2014; Haridy et al., 2018). In addition, each tooth is also proportionately larger in D. cifelli and occupies a greater portion of the dentary than in D. multidentatus, as would be expected when a single tooth row is present (Haridy et al., 2018). The dentary teeth of $D$. multidentatus are not sharp and show no recurvature unlike the known insectivore $D$. cifelli (Modesto et al., 2009). However, the broad similarities between these two taxa as well as the diminutive size of $D$. multidentatus means that this new acleistorhinid was likely to have pursued similar prey. The presence of low tuberosities on the squamosal, as well as shallow dimples and furrows on the jugal, help further characterize this specimen as a member of the Delorhynchus genus. In this holotype specimen, the jugal can be readily compared to material from $D$. cifelli, and its morphology matches the most mature specimens of $D$. cifelli despite the comparatively smaller size of this skull roof element (Haridy et al., 2016). Inspection of the rows of teeth demonstrates that the lingual row of teeth has partially eroded the labial row of teeth, which implies that the lingual row developed after the labial row. Based upon this observation, and the size disparity between teeth in each row, it is likely that rows of teeth developed on the lingual side, eroding the older row as they grew, but shifted labially to a degree sufficient to form multiple rows of teeth. $D$. multidentatus additionally possesses a wider alveolar shelf than D. cifelli, as shown in Figure 6. This feature acts as secondary support for the proposed labial drift of teeth, and is shared with some specimens of the multiple tooth-rowed eureptile Captorhinus aguti (LeBlanc and Reisz, 2015). In C. aguti, histology of the dentary reveals the presence of labial drift via asymmetric dentary growth and a resulting odontogenic region for tooth development and replacement (LeBlanc and Reisz, 2015). While the CT resolution for D. multidentatus is insufficient for determining patterns of vascularization, the enlarged alveolar shelf suggests that, as in C. aguti, D. multidentatus developed its teeth in a lingual odontogenic region. The tooth development in $D$. multidentatus appear to 
be similar to that of C. aguti in that rows of teeth in both species originated lingually and were migrated outwards towards the labial side by differential growth of the dentary bone (LeBlanc and Reisz, 2015). In contrast to the diagonal, mesial to distal tooth row development within the posterior dentary of $C$. aguti, the multiple tooth rows in $D$. multidentatus grew parallel to the dentary throughout its length (LeBlanc and Reisz, 2015). The orientation of tooth rows in $C$. aguti results in a grinding surface suitable for this taxon's omnivorous diet (Holton et al., 1997).

Multiple rows of dentary teeth have historically been an unusual condition in early Permian tetrapods, with one other occurrence in the Parareptilia, two independent developments within the captorhinids and another occurrence in a "microsaur" (Dodick and Modesto, 1995; Gee et al., 2020). The middle Triassic procolophonid parareptile Theledectes perforatus also possessed multiple rows of marginal dentition, although given the spatial, temporal and phylogenetic separation from Delorhynchus multidentatus this is regarded as a convergent trait (Gow, 1977; Modesto and Damiani, 2003). In the genus Captorhinus, C. aguti possessed multiple dentary tooth rows, while C. laticeps, C. magnus, and C. kierani were single tooth-rowed (Williston, 1909; Fox and Bowman, 1966; Kissel et al., 2002; DeBraga et al., 2019). Other small captorhinids from the early Permian with multiple tooth rows include Baeotherates fortsillensis and the genus Captorhinikos (May and Cifelli, 1998; Modesto et al., 2014; Leblanc et al., 2015; Cisneros et al., 2020a). In C. aguti and Captorhinikos, as well as other multiple tooth-rowed captorhinids from the Middle and Upper Permian, the tooth rows extend parasagitally with younger lingual and older labial teeth (Fox and Bowman, 1966; Modesto et al., 2014, 2018). B. fortsillensis differs from other captorhinids in that it possesses only two rows of dentary teeth aligned diagonally to the dentary, but it is not known whether this feature developed independently of other multiple-rowed captorhinids due to limited material (May and Cifelli, 1998; DeBraga et al., 2019). The presence of dual tooth rows has also been documented within early Permian non-amniote tetrapods, such as in the gymnarthrid "microsaur" Euryodus dalyae which possesses a partial double tooth row at the posterior edge of the dentary (Gee et al., 2020).

A recent study on extant phrynosomatid lizards Uta stansburiana and Petrosaurus mearnsi, which are normally single tooth-rowed taxa excluding specimens within said study, hypothesizes that developmental irregularities in odontogenic gene expression may result in multiple tooth rows (Scarpetta and Bell, 2020). In these cases, the specimens appear to have experienced crowding of tooth positions resulting in multiple tooth rows on an unexpanded alveolar shelf (Scarpetta and Bell, 2020). These recent findings raise the possibility of single tooth-rowed taxa being designated as possessing multiple tooth rows as a result of developmental abnormalities. Due to the specific development of multiple tooth rows in this new acleistorhinid taxon, as well as other features such as reduced skull size, we consider this hypothesis unlikely for
Delorhynchus multidentatus and believe it to be a new taxon rather than a specimen of $D$. cifelli with unusual tooth development. In D. multidentatus, the mandible contains morphologically distinct teeth with a widened alveolar shelf. In particular, the alveolar shelf is significant in that it provides room for additional tooth positions that would otherwise result in the anomalous crowding as shown in Scarpetta and Bell (2020). In contrast to the more distinct tooth rows seen in other multiple tooth-rowed taxa such as the moradisaurine Captorhinikos valensis, CT data show that some replacement teeth in this specimen have eroded into the pulp cavities of older teeth (see Figure 4) (Modesto et al., 2014), but the older teeth appear to remain functional. In Captorhinus aguti, the wide alveolar shelf present on the dentary is the product of asymmetric growth and apparently results in the labial shift of tooth rows, which is also hypothesized for D. multidentatus based on examination of tooth-bearing material (LeBlanc and Reisz, 2015). In Euryodus dalyae, the presence of multiple tooth rows differs significantly from the aforementioned taxa, as only the two posteriormost tooth positions occur in multiple rows (Gee et al., 2020). While the teeth produced in the multiple tooth rows in Euryodus are small, the alveolar shelf present in this specimen is widened, likely the result of the large coronoid process posterior to it (Gee et al., 2020). This coronoid process may have labially shifted the older, smaller teeth during ontogeny, away from the dental lamina and the teeth being produced there, leading to two functional teeth in one position. Given the proposed labial drift of $D$. multidentatus and minor overlap of teeth resulting in partial erosion of old teeth, it is possible that the condition of this acleistorhinid represents an intermediate form between what is demonstrated by Scarpetta and Bell (2020) and other multiple tooth-rowed taxa such as moradosaurines. Nevertheless, it is likely that the development of multiple tooth rows among acleistorhinids was part of the hypothesized radiation of parareptiles within Richards Spur, resulting in the retention of a second tooth row in $D$. multidentatus (MacDougall et al., 2016; Scarpetta and Bell, 2020) It is clear that early Permian tetrapods with multiple tooth rows are rare in the fossil record. Theledectes perforatus, Captorhinus aguti, Euryodus dalyae and moradosaurines such as Captorhinikos each developed dental batteries independently of one another (Fox and Bowman, 1966; Modesto and Damiani, 2003; Modesto et al., 2014; Gee et al., 2020). In each case, there is an increase in complexity of dentition without corresponding changes in dentition shape, in contrast to the change in dentition shape seen in Diadectes for the purposes of oral processing (Cope, 1880). The discovery of D. multidentatus not only contributes to the diversity of acleistorhinids within the early Permian of Oklahoma, but also documents the first case of multiple tooth rows within the Acleistorhinidae.

\section{DATA AVAILABILITY STATEMENT}

The raw data supporting the conclusions of this article will be made available by the authors, without undue reservation. 


\section{AUTHOR CONTRIBUTIONS}

DR analysed the data, wrote first draft of the article, and produced the CT figures. JB performed the neutron analysis and contributed the article. RR designed the project, contributed specimens, and contributed to the article. DS discovered specimen, prepared and contributed photographs. All authors approved the submission of this article.

\section{FUNDING}

This research was funded by an NSERC Discovery Grant to RR, the University of Toronto, and The International Center of

\section{REFERENCES}

Anderson, J. S., and Reisz, R. R. (2003). A New Microsaur (Tetrapoda: Lepospondyli) from the Lower Permian of Richards Spur (Fort Sill), Oklahoma. Can. J. Earth Sci. 40, 499-505. doi:10.1139/E02-066

Berman, D. S., Reisz, R. R., Scott, D. M., Henrici, A. C., Sumida, S. S., and Martens, T. (2000). Early Permian Bipedal Reptile. Science 290, 969-972. Available at: http://science.sciencemag.org/. doi:10.1126/science.290.5493.969

Cisneros, J. C., Angielczyk, K., Kammerer, C. F., Smith, R. M. H., Fröbisch, J., Marsicano, C. A., et al. (2020a). Captorhinid Reptiles from the Lower Permian Pedra de Fogo Formation, Piauí, Brazil: The Earliest Herbivorous Tetrapods in Gondwana. PeerJ 8, e8719. doi:10.7717/peerj.8719

Cisneros, J. C., Kammerer, C. F., Angielczyk, K. D., Fröbisch, J., Marsicano, C., Smith, R. M. H., et al. (2020b). A New Reptile from the Lower Permian of Brazil (Karutia fortunata gen. et sp. nov.) and the Interrelationships of Parareptilia. J. Syst. Palaeontology 18, 1939-1959. doi:10.1080/14772019.2020.1863487

Cisneros, J. C. (2008). Phylogenetic Relationships of Procolophonid Parareptiles with Remarks on Their Geological Record. J. Syst. Palaeontology 6, 345-366. doi:10.1017/S1477201907002350

Cope, E. D. (1878). Descriptions of Extinct Batrachia and Reptilia from the Permian Formation of Texas. Proc. Am. Philosphical Soc. 17, 505-530.

Cope, E. D. (1880). Second Contribution to the History of the Vertebrata of the Permian Formation of Texas. Proc. Am. Philosphical Soc. 19, 38-58.

Daly, E. (1969). A New Procolophonoid Reptile from the Lower Permian of Oklahoma. Soc. Sediment. Geol. 43, 676-687. Available at: https://www.jstor. org/stable/1302462. doi:10.1086/642390

DeBraga, M., Bevitt, J. J., and Reisz, R. R. (2019). A New Captorhinid from the Permian Cave System Near Richards Spur, Oklahoma, and the Taxic Diversity of Captorhinus at This Locality. Front. Earth Sci. 7, 1-12. doi:10.3389/ feart.2019.00112

Debraga, M., and Reisz, R. R. (1996). The Early Permian reptileAcleistorhinus Pteroticusand its Phylogenetic Position. J. Vertebr. Paleontol. 16, 384-395. doi:10.1080/02724634.1996.10011328

Dodick, J. T., and Modesto, S. P. (1995). The Cranial Anatomy of the Captorhinid Reptile Labidosaurikos Meachami from the Lower Permian of Oklahoma. Palaeontology 38, 687-711.

Fox, R. C., and Bowman, M. C. (1966). Osteology and Relationships of Captorhinus Aguti (Cope) (Reptilia: Captorhinomorpha). Univ. Kans. Paleontol. Inst. $11,1-79$.

Fox, R. C. (1962). Two New Pelycosaurs from the Lower Permian of Oklahoma. Available at: http://biodiversitylibrary.org/page/4392836 (Accessed January 9, 2021).

Garbe, U., Randall, T., Hughes, C., Davidson, G., Pangelis, S., and Kennedy, S. J. (2015). A New Neutron Radiography/Tomography/Imaging Station DINGO at OPAL. Phys. Proced. 69, 27-32. doi:10.1016/j.phpro.2015.07.003

Gee, B. M., Bevitt, J. J., and Reisz, R. R. (2020). Computed Tomographic Analysis of the Cranium of the Early Permian Recumbirostran 'microsaur' Euryodus
Future Science, Dinosaur Evolution Research Center, Jilin University, Changchun, Jilin Province, China.

\section{ACKNOWLEDGMENTS}

We would like to thank Bill May and Mike Feese for collection and donation of material from Richards Spur, Oklahoma. In addition, DR would like to thank Bryan Gee, Sigi Maho and Kayla Bazzana for CT segmentation assistance, and Tea Maho for photography assistance. This research was funded by an NSERC Discovery Grant to RR and The International Center of Future Science, Dinosaur Evolution Research Center, Jilin University, Changchun, Jilin Province, China, and the University of Toronto.

Dalyae Reveals New Details of the Braincase and Mandible. Pap. Palaeontol. 7, 721-749. doi:10.1002/spp2.1304

Gow, C. E. (1977). New Procolophonids from the Triassic Cynognathus Zone of South Africa. Ann. South Afr. Mus. 72, 109-124.

Haridy, Y., Macdougall, M. J., and Reisz, R. R. (2018). The Lower Jaw of the Early Permian Parareptile Delorhynchus, First Evidence of Multiple Denticulate Coronoids in a Reptile. Zool. J. Linn. Soc. 184, 791-803. doi:10.1093/ zoolinnean/zlx085

Haridy, Y., Macdougall, M. J., Scott, D., and Reisz, R. R. (2016). Ontogenetic Change in the Temporal Region of the Early Permian Parareptile Delorhynchus Cifellii and the Implications for Closure of the Temporal Fenestra in Amniotes. PLoS One 11, e0166819. doi:10.1371/ journal.pone. 0166819

Holton, N. I., Olson, E. C., and Beerbower, R. (1997). "Amniote Origins and the Discovery of Herbivory," in Amniote Origins: Completing the Transition to Land San Diego: Academic Press, 207-264.

Kissel, R. A., Dilkes, D. W., and Reisz, R. R. (2002). Captorhinus Magnus, a New Captorhinid (Amniota: Eureptilia) from the Lower Permian of Oklahoma, with New Evidence on the Homology of the astragalus. Can. J. Earth Sci. 39, 1363-1372. doi:10.1139/E02-040

Leblanc, A. R. H., Brar, A. K., May, W. J., and Reisz, R. R. (2015). Multiple ToothRowed Captorhinids from the Early Permian Fissure Fills of the Bally Mountain Locality of Oklahoma. Vert. Anat. Morph. Palaeo. 1, 35-49. Available at: https:// journals.library.ualberta.ca/vamp/index.php/VAMP/article/view/24960/18848 (Accessed July 13, 2021). doi:10.18435/b5rp4n

LeBlanc, A. R. H., and Reisz, R. R. (2015). Patterns of Tooth Development and Replacement in Captorhinid Reptiles: a Comparative Approach for Understanding the Origin of Multiple Tooth Rows. J. Vertebr. Paleontol. 35, e919928. doi:10.1080/02724634.2014.919928

Lee, S.-K., Lee, H., and Chae, D.-B. (1999). A Taxonomic Revision of Pareiasaurian Reptiles: Implications for Permian Terrestrial Palaeoecology. Mod. Geol. 21, 231-298. doi:10.23948/kshw.1999.12.2.231

MacDougall, M. J., Brocklehurst, N., and Fröbisch, J. (2019). Species Richness and Disparity of Parareptiles across the End-Permian Mass Extinction. Proc. R. Soc. B. 286, 20182572. doi:10.1098/rspb.2018.2572

MacDougall, M. J., Modesto, S. P., and Reisz, R. R. (2016). A New Reptile from the Richards Spur Locality, Oklahoma, U.S.A., and Patterns of Early Permian Parareptile Diversification. J. Vertebr. Paleontol. 36, el179641. doi:10.1080/ 02724634.2016 .1179641

MacDougall, M. J., and Reisz, R. (2012). A New Parareptile (Parareptilia, Lanthanosuchoidea) from the Early Permian of Oklahoma. J. Vertebr. Paleontol. 32, 1018-1026. doi:10.1080/ 02724634.2012 .679757

MacDougall, M. J., and Reisz, R. R. (2014). The First Record of a Nyctiphruretid Parareptile from the Early Permian of North America, with a Discussion of Parareptilian Temporal Fenestration. Zool. J. Linn. Soc. 172, 616-630. Available at: https://academic.oup.com/zoolinnean/article/172/3/616/2433414 (Accessed January 3, 2021). doi:10.1111/zoj.12180 
MacDougall, M. J., Tabor, N. J., Woodhead, J., Daoust, A. R., and Reisz, R. R. (2017). The Unique Preservational Environment of the Early Permian (Cisuralian) Fossiliferous Cave Deposits of the Richards Spur Locality, Oklahoma. Palaeogeogr. Palaeoclimatol. Palaeoecol. 475, 1-11. doi:10.1016/ j.palaeo.2017.02.019

Mann, A., McDaniel, E. J., McColville, E. R., and Maddin, H. C. (2019). Carbonodraco lundi gen et sp. Nov., the ololdest Parareptile, from Linton, Ohio, and New Insights into the Early Radiation of Reptiles. R. Soc. Open Sci. 6, 191191. doi:10.1098/rsos.191191

May, W. J., and Cifelli, R. L. (1998). Baeotherates Fortsillensis, a New Captorhinid Reptile from the Fort Sill Fissures, Lower Permian of Oklahoma. Okla. Geol. Notes 58, 128-137.

Mays, C., Bevitt, J., and Stilwell, J. (2017). Pushing the Limits of Neutron Tomography in Palaeontology: Three-Dimensional Modelling of In Situ Resin within Fossil Plants. Paleontol. Electron. 20 (3), 1-12. doi:10.26879/808

Modesto, S. P. (1999). Colobomycter Pholeterfrom the Lower Permian of Oklahoma: A Parareptile, Not a Protorothyridid. J. Vertebr. Paleontol. 19, 466-472. doi:10.1080/02724634.1999.10011159

Modesto, S. P., and Damiani, R. (2003). Taxonomic Status of Thelegnathus Browni Broom, a Procolophonid Reptile from the South African Triassic. Ann. Carnegie Mus. 72, 53-64. Available at: https://www.researchgate.net/ publication/289895921 (Accessed July 5, 2021).

Modesto, S. P., Lamb, A. J., and Reisz, R. R. (2014). The Captorhinid reptileCaptorhinikos Valensisfrom the Lower Permian Vale Formation of Texas, and the Evolution of Herbivory in Eureptiles. J. Vertebr. Paleontol. 34, 291-302. doi:10.1080/02724634.2013.809358

Modesto, S. P., Richards, C. D., Ide, O., and Sidor, C. A. (2018). The Vertebrate Fauna of the Upper Permian of Niger-X. The Mandible of the Captorhinid Reptile Moradisaurus Grandis. J. Vertebr. Paleontol. 38, e1531877. doi:10.1080/ 02724634.2018.1531877

Modesto, S. P., Scott, D. M., MacDougall, M. J., Sues, H.-D., Evans, D. C., and Reisz, R. R. (2015). The Oldest Parareptile and the Early Diversification of Reptiles. Proc. R. Soc. B. 282, 20141912. doi:10.1098/rspb.2014.1912

Modesto, S. P., Scott, D. M., and Reisz, R. R. (2009). Arthropod Remains in the Oral Cavities of Fossil Reptiles Support Inference of Early Insectivory. Biol. Lett. 5, 838-840. doi:10.1098/rsbl.2009.0326

Modesto, S. P. (2006). The Cranial Skeleton of the Early Permian Aquatic Reptile Mesosaurus Tenuidens: Implications for Relationships and Palaeobiology. Zool. J. Linn. Soc. 146, 345-368. Available at: https://academic.oup.com/zoolinnean/ article/146/3/345/2626900 (Accessed January 10, 2021). doi:10.1111/j.10963642.2006.00205.x

Reisz, R. R., Barkas, V., and Scott, D. (2002). A New Early Permian Bolosaurid Reptile from the Richards Spur Dolese Brothers Quarry, Near Fort Sill, Oklahoma. J. Vertebr. Paleontol. 22, 23-28. doi:10.1671/0272-4634(2002)022 [0023:anepbr]2.0.co;2

Reisz, R. R., Macdougall, M. J., and Modesto, S. P. (2014). A New Species of the Parareptile genusDelorhynchus, Based on Articulated Skeletal Remains from Richards Spur, Lower Permian of Oklahoma. J. Vertebr. Paleontol. 34, 1033-1043. doi:10.1080/02724634.2013.829844
Scarpetta, S. G., and Bell, C. J. (2020). Novel and Bizarre Abnormalities of the Tooth Row in Side-Blotched Lizards ( Uta ) and Rock Lizards ( Petrosaurus ). Anat. Rec. 303, 2014-2025. doi:10.1002/ar.24279

Sullivan, C., Reisz, R. R., and May, W. J. (2000). Large Dissorophoid Skeletal Elements from the Lower Permian Richards Spur Fissures, Oklahoma, and Their Paleoecological Implications. J. Vertebr. Paleontol. 20, 456-461. doi:10.1671/0272-4634(2000)020[0456:ldseft]2.0.co;2

Tsuji, L. A., Müller, J., Reisz, R. R., and Uller, J. M. (2012). Anatomy ofEmeroleter Levisand the Phylogeny of the Nycteroleter Parareptiles. J. Vertebr. Paleontol. 32, 45-67. doi:10.1080/02724634.2012.626004

Tsuji, L. A., Müller, J., and Reisz, R. R. (2010). Microleter Mckinzieorumgen. et sp. nov. from the Lower Permian of Oklahoma: The Basalmost Parareptile from Laurasia. J. Syst. Palaeontology 8, 245-255. doi:10.1080/14772010903461099

Vaughn, P. P. (1958). On a New Pelycosaur from the Lower Permian of Oklahoma, and on the Origin of the Family Caseidae. J. Paleontol. 32, 981-991. Available at: https://www.jstor.org/stable/1300717 (Accessed January 9, 2021).

Verrière, A., Brocklehurst, N., and Fröbisch, J. (2016). Assessing the Completeness of the Fossil Record: Comparison of Different Methods Applied to Parareptilian Tetrapods (Vertebrata: Sauropsida). Paleobiology 42, 680-695. doi:10.1017/ pab.2016.26

Whitlock, J. A., and Richman, J. M. (2013). Biology of Tooth Replacement in Amniotes. Int. J. Oral Sci. 5, 66-70. doi:10.1038/ijos.2013.36

Williston, S. W. (1909). New or Little Known Permian Vertebrates. Pariotichus. Biol. Bull. 17, 241-255. doi:10.2307/1536117

Woodhead, J., Reisz, R., Fox, D., Drysdale, R., Hellstrom, J., Maas, R., et al. (2010). Speleothem Climate Records from Deep Time? Exploring the Potential with an Example from the Permian. Geology 38, 455-458. doi:10.1130/G30354.1

Conflict of Interest: The authors declare that the research was conducted in the absence of any commercial or financial relationships that could be construed as a potential conflict of interest.

The reviewer (ARHL) declared a past collaboration with one of the authors (RR) to the handling editor.

Publisher's Note: All claims expressed in this article are solely those of the authors and do not necessarily represent those of their affiliated organizations, or those of the publisher, the editors and the reviewers. Any product that may be evaluated in this article, or claim that may be made by its manufacturer, is not guaranteed or endorsed by the publisher.

Copyright (c) 2021 Rowe, Scott, Bevitt and Reisz. This is an open-access article distributed under the terms of the Creative Commons Attribution License (CC BY). The use, distribution or reproduction in other forums is permitted, provided the original author(s) and the copyright owner(s) are credited and that the original publication in this journal is cited, in accordance with accepted academic practice. No use, distribution or reproduction is permitted which does not comply with these terms. 